Aysun Ata*, Eren Er, Ferda Evin, Hafize Işıklar, Nushaba Abdullayev, Günay Demir, Samim Özen, Yasemin Atik Altınok, Şükran Darcan and Damla Gökşen

\title{
Treatment and long-term follow-up of patients diagnosed with type 1 diabetes mellitus before age 5
}

https://doi.org/10.1515/jpem-2020-0205

Received April 20, 2020; accepted November 19, 2020; published online December 18, 2020

\section{Abstract}

Objectives: This study aimed to determine the effects of continuous subcutaneous insulin infusion (CSII) treatment on anthropometric measurements, mean HbA1c, and insulin dosage in patients diagnosed under 5 years of age and compare with multiple-dose injection therapy (MDI).

Methods: Children with type 1 diabetes mellitus, diagnosed $<5$ years since 2000 and their 19-year follow-up were evaluated retrospectively. Weight, height, body mass index (BMI), blood pressure, and HbA1c values were recorded for each visit.

Results: Hundred and five patients (58.1\% female, $41.9 \%$ male) were included in the study. Sixty-three $(60 \%)$ patients were treated by CSII and $42(40 \%)$ by MDI. Mean age at diagnosis was $2.68 \pm 1.42$ and $3.29 \pm 1.30$ years respectively. Mean follow-up was $7.42 \pm 4.76$ and $6.01 \pm 4.41$ years respectively. For each group, weight standard deviation score (SDS) increased significantly in the first year after the diagnosis $(\mathrm{p}<0.001)$, and with the onset of puberty weight SDS decreased significantly $(\mathrm{p}<0.001)$. The trend of weight and BMI SDS changes over the years showed similar characteristics in both groups. During follow-up height SDS was similar in both groups except in Tanner stage 5 . When puberty was completed, mean height SDS was $0.51 \pm 1.03$ in CSII and $-0.31 \pm 0.75$ in the MDI group (p: 0.029). Mean HbA1c was significantly lower in the CSII group (7.62 \pm 0.82 and $8.17 \pm 1.22$ respectively). Systolic and

\footnotetext{
*Corresponding author: Aysun Ata, MD, Department of Pediatrics, Division of Pediatric Endocrinology, Faculty of Medicine, Ege University, 35100, Izmir, Turkey, Phone: +90 232 3901230, +90 505 4952030, Fax: +90 232 3886366, E-mail: draysunkaya@gmail.com Eren Er, Ferda Evin, Hafize Işıklar, Günay Demir, Samim Özen, Yasemin Atik Altınok, Şükran Darcan and Damla Gökşen, Department of Pediatrics, Division of Pediatric Endocrinology, Faculty of Medicine, Ege University, Izmir, Turkey

Nushaba Abdullayev, Department of Pediatrics, Faculty of Medicine, Ege University, Izmir, Turkey
}

¿ Open Access. ๑ 2020 Aysun Ata et al., published by De Gruyter. (cc) BY License. diastolic blood pressure change trends during the follow-up were also similar in both groups.

Conclusions: CSII treatment had positive effects on metabolic control and height SDS in patients with early-onset diabetes without increasing BMI.

Keywords: height; insulin pump; metabolic control; preschool type 1 diabetes.

\section{Introduction}

Type 1 diabetes mellitus (T1DM) is one of the most common chronic diseases affecting more than one million children and adolescents globally $[1,2]$. There is a worldwide increase in the incidence of T1DM, especially in young children under the age of 6 years old $[3,4]$. In this age group, unpredictable feeding, inconsistent physical activity, parent-dependent eating habits, living with diabetes during the whole pubertal period complicate diabetes management and make it difficult to achieve good metabolic control [5-8]. Recurrent episodes of hypoglycemia, especially at young ages, may cause short- and long-term adverse effects on cognitive function [7]. Impaired growth is a well-documented other complication of diabetes; studies suggest that good metabolic control is crucial for normal growth $[7,8]$. Continuous subcutaneous insulin infusion (CSII) therapy reduces HbA1c and complication rates without increasing severe hypoglycemia. Considering all these data, CSII therapy is the preferred method of insulin administration for young children (aged $<7$ years) with T1DM [9]. This study aims to compare metabolic control, to assess growth parameters and frequency of diabetic ketoacidosis (DKA), hospitalization and complications within two treatment modalities during follow-up.

\section{Materials and methods}

This is a single-center retrospective study, designed in pediatric T1DM patients who were diagnosed before 5 years of age. Patients who applied to a university hospital between 2000 and 2019, who 
were diagnosed with T1DM according to International Society of Pediatric and Adolescent Diabetes/International Diabetes Federation (ISPAD/IDF) guidelines [10], were included. Patients were excluded if they had other underlying conditions that could affect glycemic control and growth such as uncontrolled thyroid disease, steroid usage, and whose medical records were insufficient. Clinical and laboratory findings, weight, height, Tanner stage, as well as complete follow-up data were gathered retrospectively from patients' files.

Standing height was measured to the nearest millimeter using a SECA264 stadiometer, weight was measured using an electronic scale to the nearest $100 \mathrm{~g}$. Height, weight, and BMI were converted to Z scores using Turkish children references [11]. Blood pressure was measured with a standard sphygmomanometer and appropriate pediatric cuff. All auxological parameters and blood pressure standard deviation scores were calculated by a computer program for Turkish children [12]. CSII was initiated by a training program by a specialist nurse and a pediatric endocrinologist. Carbohydrate counting was given by a specialist dietician for patients (if age was appropriate) and caregivers, minimum 3 months before CSII application. On the other hand, while carbohydrate counting, education was given simultaneously if the family prefers CSII treatment at the time of diagnosis. MDI protocol was applied as long-acting and short-acting insulin 4-5 times a day (glargine/detemir and aspart/glulisine/lispro). Insulin (units/kg/day) was calculated at each visit for all patients. Upon transfer to adult clinics, diabetic patients were examined routinely and HbA1c was measured during 3 months of intervals. For the study group, all necessary information up to the end of 2019 was recorded from patients' archive files. For girls, the first detection of the breast budding, for boys first detection of $4 \mathrm{~mL}$ testis volume were accepted as Tanner stage 2. For girls, menarche date and for boys, testis volume $20-25 \mathrm{~mL}$ were accepted as Tanner stage 5.

DKA was diagnosed according to the International Society of Pediatric and Adolescent Diabetes/International Diabetes Federation (ISPAD/IDF) guidelines [13]. The target HbA1c of the clinic was 7.5\% (ISPAD). HbA1c levels were obtained from the clinical medical records and annual mean HbA1c was calculated. HbA1c was measured by turbidimetric inhibition immunoassay (Roche Cobas c513 analyzer using the Tina quant ${ }^{\circledR}$ HbA1c Gen. 3 assay, Germany). The study was approved by the Ege University Medical Ethics Committee (approval number: 20-1.1T/57). Written, informed consent was obtained from all participants and their parents.

\section{Statistical analysis}

Categorical data were described using observed frequencies and percentages, and continuous variables were summarized by their means and standard deviations (or medians and interquartile ranges in case of serious deviations from normality) with a statistical package (SPSS Inc., version 21.0, Chicago, IL, USA). Nonparametric Brunner and Langer model (F1-LD-F2) was used to testing group effects by using web-based software (R software, version 3.3.1, package: nparLD, R Foundation for Statistical Computing, Vienna, Austria; http://r-project.org). In the method, the hypotheses are formulated in terms of distribution functions of experimental factors, and the effect of these factors is estimated by relative marginal effects. Also, Wald-type and analysis of variance (ANOVA)-type test statistics are used in this nonparametric model. In all studies, $\mathrm{p}$ values $<0.05$ were considered to be statistically significant.

\section{Results}

After the first evaluation for eligibility data, 105 patients out of 141 were appropriate for the study group. Sixty-one $(58.1 \%)$ of patients were female and $44(41.9 \%)$ were male. A total of $63(60 \%)$ patients were treated by CSII and 42 $(40 \%)$ by MDI. CSII was initiated mean $2.41 \pm 0.33$ years after diagnosis. In 10 patients, CSII was initiated at the time of diagnosis.

Fifty-five patients were on MiniMed ${ }^{\circledR}$ Paradigm ${ }^{\circledR}$ VEO, eight patients on Medtronic Minimed ${ }^{\circledR} 640 \mathrm{G}^{\circledR}$, and during follow-up, 12 patients changed from MiniMed ${ }^{\circledR}$ Paradigm $^{\circledR}$ VEO to $640 G^{\circledR}$. Twenty-six patients were using continuous glucose monitoring (CGM) with pump therapy (Sensor augmented pump), nine of them were using Paradigm ${ }^{\circledR}$ VEO pump with low glucose suspend function, 17 patients were using $640 \mathrm{G}^{\circledR}$ pumps with predictive low glucose suspend function. No patient was using a sensor in the MDI group.

Mean age at diagnosis in CSII and MDI group was $2.68 \pm 1.42$ and $3.29 \pm 1.30$ years (p: 0.025), the mean duration of T1DM was $7.42 \pm 4.76$ and $6.01 \pm 4.41$ years, respectively. Sixty-six $(62.8 \%)$ patients were admitted at the time of diagnosis and $39(37.2 \%)$ patients for follow-up.

In the MDI group, 28 (66\%) patients performed carbohydrate counting, while 14 (34\%) patients deemed unsuitable or unwilling for carbohydrate counting and performed an exchange nutrition plan.

At the time of diagnosis, mean weight standart deviation score (SDS) and height SDS were: $-0.24 \pm 1.14$ and $-0.16 \pm 1.1$ respectively for all the study groups (Table 1). During follow-up, in the first year after the diagnosis, weight SDS change was $0.3 \pm 0.95$ SD and increased significantly $(\mathrm{p}<0.001)$. The change in weight SDS in the follow-up period was not different between CSII and MDI groups ( $\mathrm{p}: 0.90$ ).

In the whole study group, mean BMI SDS at the time of diagnosis was $-0.09 \pm 1.25$ and increased significantly to $0.62 \pm 0.96$ in the first year of follow-up. With puberty, BMI SDS decreased to $-0.10 \pm 1.07$ ( $p<0.001)$, and it was preserved till puberty was completed $(-0.07 \pm 1.2)$. Changes in BMI SDS in the follow-up period were not different between CSII and MDI groups (p: 0.58) and in between sensor augmented pump (SAP) and standard pump groups (p: 0.64). 
Table 1: Auxologic measurements of patients as mean \pm SD.

\begin{tabular}{|c|c|c|c|c|c|c|}
\hline & & $\mathbf{n}$ & Age, year & Weight SDS & Height SDS & BMI SDS \\
\hline \multirow[t]{2}{*}{ Diagnosis } & CSII & 44 & $2.68 \pm 1.42$ & $-0.16 \pm 1.23$ & $-0.12 \pm 0.96$ & $0.01 \pm 1.24$ \\
\hline & MDI & 26 & $3.29 \pm 1.3$ & $-0.37 \pm 0.99$ & $-0.22 \pm 1.13$ & $-0.25 \pm 1.28$ \\
\hline$p$-Value & & & & 0.491 & 0.885 & 0.377 \\
\hline \multirow[t]{2}{*}{ First year } & CSII & 50 & $3.75 \pm 1.43$ & $0.4 \pm 1.07$ & $-0.15 \pm 1.09$ & $0.75 \pm 0.97$ \\
\hline & MDI & 31 & $4.36 \pm 1.28$ & $0.15 \pm 0.72$ & $-0.23 \pm 0.93$ & $0.41 \pm 0.92$ \\
\hline p-Value & & & & 0.242 & 0.773 & 0.043 \\
\hline \multirow[t]{2}{*}{ Second year } & CSII & 49 & $4.69 \pm 1.41$ & $0.41 \pm 0.98$ & $-0.16 \pm 1.08$ & $0.68 \pm 0.99$ \\
\hline & MDI & 29 & $5.24 \pm 1.36$ & $0.30 \pm 0.89$ & $-0.09 \pm 0.84$ & $0.46 \pm 0.96$ \\
\hline p-Value & & & & 0.629 & 0.770 & 0.364 \\
\hline \multirow[t]{2}{*}{ Fifth year } & CSII & 40 & $7.79 \pm 1.45$ & $0.34 \pm 1.17$ & $0.26 \pm 1.2$ & $0.29 \pm 1.14$ \\
\hline & MDI & 24 & $8.03 \pm 1.36$ & $0.26 \pm 0.92$ & $0.04 \pm 0.93$ & $0.19 \pm 0.86$ \\
\hline p-Value & & & & 0.774 & 0.448 & 0.716 \\
\hline \multirow[t]{2}{*}{ Tanner 2} & CSII & 33 & $10.2 \pm 1.1$ & $0.03 \pm 1.1$ & $0.01 \pm 1.16$ & $-0.03 \pm 1.08$ \\
\hline & MDI & 14 & $10.7 \pm 1.21$ & $-0.32 \pm 1.02$ & $-0.25 \pm 0.84$ & $-0.28 \pm 1.06$ \\
\hline p-Value & & & & 0.298 & 0.447 & 0.728 \\
\hline \multirow[t]{2}{*}{ Tanner 5} & CSII & 21 & $13.29 \pm 1.48$ & $0.1 \pm 1.21$ & $0.51 \pm 1.03$ & $-0.08 \pm 1.09$ \\
\hline & MDI & 9 & $14.1 \pm 0.98$ & $-0.18 \pm 1.53$ & $-0.31 \pm 0.75$ & $-0.06 \pm 1.51$ \\
\hline $\mathrm{p}$-Value & & & & 0.585 & 0.029 & 0.972 \\
\hline
\end{tabular}

CSII, continuous subcutaneous insulin infusion; MDI, multiple dose injection; SDS, standard deviation score; BMI, body mass index. Bold values in the table are significant $p$ values.

Three (4.8\%) patients in the CSII group and two (4.8\%) patients in the MDI group were obese on the last outpatient visit data according to WHO criteria [14].

Mean height SDS was $-0.22 \pm 1.13$ at the time of diagnosis (Figure 1) and till Tanner stage 5, there was no difference between CSII and MDI groups, but in Tanner stage 5 (n: 30), mean height SDS was $0.51 \pm 1.03$ in CSII and $-0.31 \pm 0.75$ in the MDI group (p: 0.029). Target height SDSs of CSII and MDI groups were similar, $-0.25 \pm 0.7$ and $-0.25 \pm 0.97$, respectively (p: 0.982).

Systolic and diastolic blood pressure SDSs over the years between CSII and MDI groups were similar (p: 0.29 and 0.38 , respectively).

The mean HbA1c value at the end of the first year was $7.37 \pm 0.78 \%$ in CSII and $7.33 \pm 0.81 \%$ in the MDI group (p: 0.07). Mean HBA1c was significantly lower in the CSII

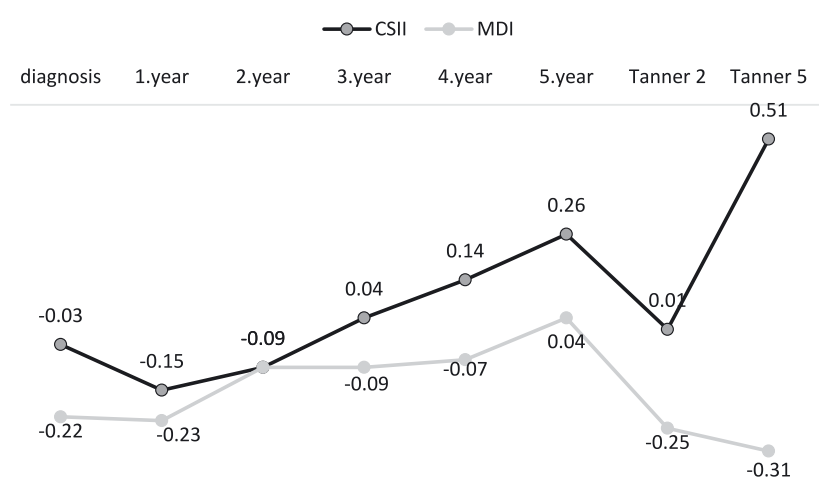

Figure 1: Height SDS of patients. group during the 15-year follow-up period $(\mathrm{p}<0.001)$ (7.6 \pm 0.82 and $8.17 \pm 1.22$, respectively) (Figure 2). In the subgroup analysis of CSII, SAP patients had lower mean HbA1c than standard CSII patients, $7.30 \pm 0.73 \%$ and $7.84 \pm 0.83 \%$, respectively (p: 0.012 ). Total insulin dose and basal insulin ratio were similar between CSII and MDI groups until puberty. With the onset of puberty, basal insulin ratio and total insulin dose were significantly decreased in the CSII group (p: 0.029 and 0.018, respectively) (Table 2).

Number of hospitalizations [median 0.32 (0.06-3.63) times/year in CSII and $0.29(0-1.19)$ in MDI group (p: 0.35)] and ketoacidosis attacks [median 0.04 (0-1.21) attacks/year in CSII and 0.07 (0-1.19) attacks/year in the MDI group (p: 0.41)] were not different between the two groups throughout the follow-up years.

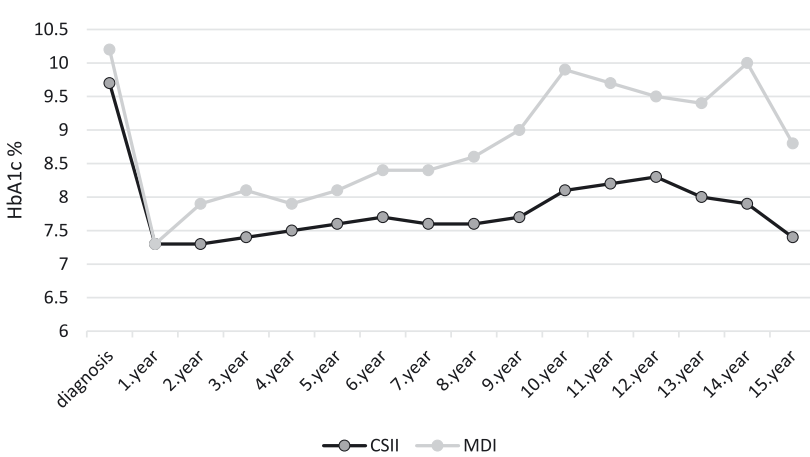

Figure 2: HbA1c variability during follow-up period. 
Table 2: Total insulin dose, basal insulin ratio during follow-up period.

\begin{tabular}{|c|c|c|c|c|c|c|c|c|c|c|}
\hline & \multicolumn{5}{|c|}{ Total insulin dose, $\mathrm{U} / \mathrm{kg} / \mathrm{day}$} & \multicolumn{5}{|c|}{ Basal insulin/total insulin ratio, \% } \\
\hline & \multicolumn{2}{|r|}{ CSII } & \multicolumn{2}{|r|}{ MDI } & \multirow[t]{2}{*}{ p-Value } & \multicolumn{2}{|r|}{ CSII } & \multicolumn{2}{|r|}{ MDI } & \multirow[t]{2}{*}{ p-Value } \\
\hline & $\mathbf{n}$ & Mean \pm SD & $\mathbf{n}$ & Mean \pm SD & & $\mathbf{n}$ & Mean \pm SD & $\mathbf{n}$ & Mean \pm SD & \\
\hline Diagnosis & 44 & $0.87 \pm 0.57$ & 26 & $0.82 \pm 0.29$ & 0.759 & 44 & $34.02 \pm 14.04$ & 26 & $36.22 \pm 14.42$ & 0.554 \\
\hline First year & 50 & $0.81 \pm 0.23$ & 31 & $0.79 \pm 0.21$ & 0.679 & 50 & $38.92 \pm 11.01$ & 31 & $45.17 \pm 15.05$ & 0.055 \\
\hline Second year & 49 & $0.81 \pm 0.22$ & 29 & $0.80 \pm 0.22$ & 0.826 & 49 & $41.99 \pm 13.14$ & 29 & $46.38 \pm 15.12$ & 0.237 \\
\hline Third year & 44 & $0.80 \pm 0.19$ & 18 & $0.89 \pm 0.25$ & 0.118 & 44 & $43.50 \pm 13.30$ & 18 & $44.57 \pm 16.90$ & 0.793 \\
\hline Fourth year & 39 & $0.84 \pm 0.21$ & 19 & $0.96 \pm 0.28$ & 0.063 & 39 & $40.30 \pm 9.38$ & 19 & $48.81 \pm 16.24$ & 0.014 \\
\hline Fifth year & 33 & $0.81 \pm 0.15$ & 21 & $0.91 \pm 0.28$ & 0.125 & 33 & $40.90 \pm 8.02$ & 21 & $47.44 \pm 16.15$ & 0.096 \\
\hline Tanner 2 & 33 & $0.86 \pm 0.19$ & 14 & $1.02 \pm 0.22$ & 0.029 & 33 & $39.88 \pm 8.30$ & 14 & $47.91 \pm 12.99$ & 0.018 \\
\hline Tanner 5 & 21 & $0.94 \pm 0.23$ & 9 & $0.99 \pm 0.28$ & 0.656 & 21 & $45.35 \pm 12.96$ & 9 & $39.76 \pm 13.52$ & 0.348 \\
\hline
\end{tabular}

CSII, continuous subcutaneous insulin infusion; MDI, multiple dose injection; SD, standard deviation. Bold values in the table are significant $\mathrm{p}$ values.

The incidence of complications was too low to draw any meaningful conclusions regarding the relative risk or benefits of either treatment. Three (6.5\%) patients in the CSII group and four (9\%) patients in the MDI group, totally seven (6.6\%) patients developed persistent microalbuminuria. Three (4.9\%) patients in the CSII group and three $(6.8 \%)$ patients in the MDI group, totally six (5.7\%) patients developed neuropathy. Chronic autoimmune thyroiditis was detected in 15 (14.2\%) patients, and celiac disease was detected in three (2.8\%) patients.

\section{Discussion}

This study aimed to evaluate the difference of auxological findings and metabolic control in children with T1DM using either CSII or MDI. In the Prospective Diabetes Follow-up Registry (DPV) study, in children under 6 years of age, mean HbA1c was $7.4 \%$ using $74 \%$ CSII treatment [15]. Numerous observational studies with type 1 diabetes have reported decreases in HbA1c levels with CSII without increasing the risk of hypoglycemia $[16,17]$. Our results supporting this demonstrate a better glycemic control in the CSII group (HbA1c: 7.62\%) compared to the MDI group (HbA1c: 8.17\%), below the average of our country $[18,19]$. In the outcomes of the 2016-2018 T1D exchange registry report, CGM use increased in pediatric age groups; especially under 5 years of age (51\%) and mean HbA1c was lowest in the SAP group. Under 13 years of age, mean HbA1c is $9.0 \%$ in MDI (n: 75) and $8.7 \%$ in standard pump group (n: 72 ) and $7.9 \%$ in SAP (n: 63) group [20]. Similarly in our study, the best HbA1c was achieved in patients using SAP therapy.

It is known that both boys and girls with T1DM are heavier and taller throughout childhood than healthy children. By contrast, in a study with 184 children with T1DM found that children aged 5-10 years at diagnosis were taller than controls at the same age, while those diagnosed at $<5$ years of age were shorter [21]. Alterations in growth have been reported in children with T1DM, although with discordant findings in different studies [22-26]. In the SCIPI RCT study, during one-year prospective follow-up, there was no significant difference in change of BMI or height SDS between CSII and MDI in pediatric patients, but as the 1-year follow up is not enough to conclude height [27]. For our cases, they were not taller or heavier than healthy peers at the time of diagnosis; mean weight SDS was: $-0.24 \pm 1.14$ and height SDS was $-0.16 \pm 1.1$, but after puberty height was higher in CSII patients than in MDI patients, although target height SDS of both groups was not different. MDI group height SDS was similar to their target height SDS. In our study, the final height could not be compared because very few patients were over 18 years old when the study was completed. Based on the information that, as puberty completed, a girl has reached $99 \%$ of her adult height at a bone age of 15 years and has a small amount of height growth left from this point, height SDS values were compared in children who completed puberty [28]. However, there is evidence of a secular trend in the heights of children over the last 20 years [29]. Considering this, the CSII group may demonstrate the expected growth, while the MDI group may not. This height difference may be due to a difference in metabolic control. Bonfig et al. collected the final adult height data of 1685 patients with T1DM who were diagnosed before the age of 10 years, notably, the group with HbA1c $<7 \%$ had a final adult height SDS of +0.030 , groups with HbA1c of $7-8 \%$ and $>8 \%$ had final adult SDS values of -0.122 and -0.308 , respectively; this suggested that poor glycemic control was associated with a slight reduction in final adult height [29]. Similarly, our MDI group patients' HbA1c was $8.17 \%$ and mean height SDS was -0.31 . This also alone 
cannot explain the +0.75 SDS increase from target adult height SDS in the CSII group, there should be a factor that influences pubertal growth spurt, as the height difference in our study groups occurs by then. This may be explained by studies of higher IGF-1 levels of good metabolic control than poor metabolic control patients [30]. They also have demonstrated high GH and low IGF-1 level in patients with T1DM in poor control like all chronic diseases affecting growth [21, 31], so IGF-1 levels were strongly correlated with height [24]. Because our study was retrospective, IGF-1 levels were not evaluated.

In our study group, CSII treatment was not started at the time of diagnosis in 53 patients (84\%). This may seem like a limitation, but we think that it did not affect our results regarding height, since in all patients CSII therapy was applied before puberty and the mean follow-up period of patients who completed puberty was $11.8 \pm 3.5$ years.

In the DCCT study, short adult stature is associated with microvascular complications in type 1 diabetes and short stature was independently associated with both diabetic nephropathy and laser-treated retinopathy in addition to the conventional risk factors such as duration of diabetes, A1C, blood pressure [32]. These results suggest that diabetes influences height by different mechanisms in addition to IGF-1 and these mechanisms are also associated with microvascular complications. This can be studied by the effect of glycemic variability; at the same HbA1c values, patients may have different glycemic variabilities and increased variability can affect both complications and IGF-1/GH axis.

As known anabolic effects of insulin, and by using intensive insulin regimen, excessive weight gain and obesity are another common problem in children with T1DM. Increased BMI in youth with T1DM has been reported in clinic-based and national cohorts and is associated with a more atherogenic cardiovascular disease risk profile [33, 34]. In a retrospective study from Australia 20-year follow-up of 1975 children with type 1 diabetes, the proportion of overweight and obese children was higher than that in the general Australian pediatric population [35]. In a study, T1DM patients were found to be less active than their peers and this may contribute to adiposity [36]. In our study population, interestingly obesity ratio was lower than the general Turkish pediatric population (7.5-8.5\%) [37].

As a controversial issue, CSII was associated with a significant increase in the incidence of reported DKA. Notably, the increased risk of DKA was significant in trials comparing CSII with conventional insulin therapy, whereas only a nonsignificant trend toward increased risk was observed in comparisons with basal-bolus MDI [38-40]. In our study, the DKA attack number or hospitalization number was not different between groups.
When the long-term effects of CSII treatment were investigated, it is hoped and estimated to reduce microvascular complication rates. Although studies have been shown that CSII treatment reduces arterial stiffness, decreases the frequency of retinopathy, reduces the progression of microalbuminuria, more studies are needed [41-43]. In our study, the number of complications was insufficient to make a statistical interpretation.

According to a SWEET prospective study, in 16570 children, daily insulin dose $(\mathrm{U} / \mathrm{kg} / \mathrm{D})$ remained decreased when treated with CSII compared to MDI [44]. In our study subgroup analysis, also there is a tendency of low insulin dosage and basal ratio in the CSII group, only Tanner stage 2 was found to be statistically significant.

\section{Conclusion}

CSII treatment had positive effects on metabolic control and height SDS in patients with early-onset diabetes (under 5 years old) without increasing BMI and DKA. More studies are needed to find the causative agent of preventing pubertal spurt in diabetic patients, its relationship to glycemic variability may be a responsible factor.

\section{Limitations}

The current study was a retrospective study of one tertiary center patients in a developed city of Turkey; thus, cases of selection bias cannot be completely ruled out. Moreover, the small number of subgroups may not provide sufficient statistical power to fully elucidate the relationships between variables. Social security system payment is very little for pump therapy and additional reservoir and set fees are paid by families. Continuous glucose monitoring systems are out of insurance. Besides very few centers can't still apply CSII, this may lead to better socioeconomic status families that reached to us for CSII application. This may also be the cause of better metabolic control of our patients than Turkey's mean HbA1cs. We could not determine the glycemic variability and hypoglycemia because of the retrospective design of our study.

Author contributions: Aysun Ata: methodology, conceptualization, writing; Eren Er: software, investigation; Hafize Işıllar: investigation; Günay Demir: software, investigation; Yasemin Atik Altınok: investigation; Nushabe Abdullayev: investigation; Samim Özen: methodology, supervision; Şükran Darcan: project administration; Damla Gökşen: writing, reviewing, editing. All the authors accepted 
responsibility for the entire content of this submitted article and approved submission.

Research funding: None declared.

Conflict of interest: The funding organization(s) played no role in the study design; in the collection, analysis, and interpretation of data; in the writing of the report; or in the decision to submit the report for publication.

Informed consent: Informed consent was obtained from all individuals included in this study.

Ethical approval: Research involving human subjects complied with all relevant national regulations, institutional policies and is in accordance with the tenets of the Helsinki Declaration (as revised in 2013), and has been approved by the authors' Institutional Review Board (Ege University Ethics Comitee) or equivalent committee (approval number:20-1.1T/57).

\section{References}

1. Kernick D, Chew-Graham CA, O'Flynn N. Clinical assessment and management of multimorbidity: a NICE guideline. Br J Gen Pract 2017;67:235-6.

2. International Diabetes Federation. IDF diabetes atlas. Brussels: International Diabetes Federation; 2015.

3. Yeşilkaya E, Cinaz P, Andıran N, Bideci A, Hatun Ş, Sarı E, et al. First report on the nationwide incidence and prevalence of Type 1 diabetes among children in Turkey. Diabet Med 2017;34:405-10.

4. Couper JJ, Haller MJ, Greenbaum CJ, Ziegler A-G, Wherrett DK, Knip $M$, et al. ISPAD clinical practice consensus guidelines 2018: stages of type 1 diabetes in children and adolescents. Pediatr Diabetes 2018;19:20-7.

5. Cerutti F, Bruno G, Chiarelli F, Lorini R, Meschi F, Sacchetti C. Younger age at onset and sex predict celiac disease in children and adolescents with type 1 diabetes: an Italian multicenter study. Diabetes Care 2004;27:1294-8.

6. Pala L, Dicembrini I, Mannucci E. Continuous subcutaneous insulin infusion vs modern multiple injection regimens in type 1 diabetes: an updated meta-analysis of randomized clinical trials. Acta Diabetol 2019;56:973-80.

7. Olsen BS, Sjølie AK, Hougaard P, Johannesen J, Marinelli K, Jacobsen BB, et al. The significance of the prepubertal diabetes duration for the development of retinopathy and nephropathy in patients with type 1 diabetes. J Diabet Complicat 2004;18:160-4.

8. Waden J, Forsblom C, Thorn LM, Saraheimo M, Rosengard-Barlund M, Heikkila 0 , et al. Adult stature and diabetes complications in patients with type 1 diabetes: the FinnDiane study and the diabetes control and complications trial. Diabetes 2009;58: 1914-20.

9. Sundberg F, Barnard K, Cato A, de Beaufort C, DiMeglio LA, Dooley $\mathrm{G}$, et al. Managing diabetes in preschool children. Pediatr Diabetes 2017;18:499-517.

10. Mayer-Davis EJ, Kahkoska AR, Jefferies C, Dabelea D, Balde N, Gong CX, et al. ISPAD Clinical Practice Consensus Guidelines
2018: definition, epidemiology, and classification of diabetes in children and adolescents. Pediatr Diabetes 2018;19:7-19.

11. Neyzi O, Bundak R, Gökçay G, Günöz H, Furman A, Darendeliler F, et al. Reference values for weight, height, head circumference, and body mass index in Turkish children. J Clin Res Pediatr Endocrinol 2015;7:280-93.

12. Demir K, Konakçı E, Özkaya G, Kasap Demir B, Özen S, Aydın M, et al. New features for child metrics: further growth references and blood pressure calculations. J Clin Res Pediatr Endocrinol 2019;0:0-0.

13. Wolfsdorf JI, Glaser N, Agus M, Fritsch M, Hanas R, Rewers A, et al. ISPAD clinical practice consensus guidelines 2018: diabetic ketoacidosis and the hyperglycemic hyperosmolar state. Pediatr Diabetes 2018;19:155-77.

14. De Onis M, Lobstein T. Defining obesity risk status in the general childhood population: which cut-offs should we use? Int J Pediatr Obes [Internet] 2010;5:458-60.

15. Maahs DM, Hermann JM, DuBose SN, Miller KM, Heidtmann B, DiMeglio LA, et al. Contrasting the clinical care and outcomes of 2,622 children with type 1 diabetes less than 6 years of age in the United States T1D Exchange and German/Austrian DPV registries. Diabetologia 2014;57:1578-85.

16. Senn J-D, Fischli S, Slahor L, Schelbert S, Henzen C. Long-term effects of initiating continuous subcutaneous insulin infusion (CSII) and continuous glucose monitoring (CGM) in people with type 1 diabetes and unsatisfactory diabetes control. J Clin Med 2019;8:394.

17. El-Laboudi AH, Godsland IF, Johnston DG, Oliver NS. Measures of glycemic variability in type 1 diabetes and the effect of real-time continuous glucose monitoring. Diabetes Technol Therapeut 2016;18:806-12.

18. Hatun Ş, Demirbilek H, Darcan Ş, Yüksel A, Binay C, Şimşek DG, et al. Evaluation of therapeutics management patterns and glycemic control of pediatric type 1 diabetes mellitus patients in Turkey: a nationwide cross-sectional study. Diabetes Res Clin Pract 2016;119:32-40.

19. Yetim A, Alikaşifoğlu M, Baş F, Eliaçık K, Çığ G, Erginöz E, et al. Glycemic control and health behaviours in adolescents with type 1 diabetes. Turk J Pediatr 2018;60:244.

20. Foster NC, Beck RW, Miller KM, Clements MA, Rickels MR, DiMeglio RA, et al. State of type 1 diabetes management and outcomes from the T1D exchange in 2016-2018. Diabetes Technol Therapeut 2019;21:66-72.

21. Massa G, Dooms L, Bouillon R, Vanderschueren-Lodeweyckx $M$. Serum levels of growth hormone-binding protein and insulin-like growth factor I in children and adolescents with Type 1 (insulin-dependent) diabetes mellitus. Diabetologia 1993;36:239-43.

22. Al-Agha AE, Aljuhani FM, Almunami BA, Meftah EA, Sultan RA, Sultan RA, et al. Growth status of children and adolescents with type 1 diabetes mellitus in Jeddah, Saudi Arabia: a crosssectional study. Curr Pediatr Res 2018;22:6.

23. Brown M, Ahmed ML, Clayton KL, Dunger DB. Growth during childhood and final height in type 1 diabetes. Diabet Med 1994; 11:182-7.

24. Elamin A, Hussein O, Tuvemo T. Growth, puberty, and final height in children with Type 1 diabetes. J Diabet Complicat 2006;20:252-6.

25. Demir K. Growth of children with type 1 diabetes mellitus. J Clin Res Pediatr Endocrinol 2010;2:72-7. 
26. Khadilkar A, Chiplonkar S, Borade A, Khadilkar V, Parthasarathy L, Mallade B. Growth status of children and adolescents with type 1 diabetes mellitus. Indian J Endocrinol Metab 2013;17:1057.

27. Mameli C, Scaramuzza AE, Ho J, Cardona-Hernandez R, Suarez-Ortega L, Zuccotti GV, et al. A 7-year follow-up retrospective, international, multicenter study of insulin pump therapy in children and adolescents with type 1 diabetes. Acta Diabetol 2014;51:205-10.

28. Khadilkar V, Bajpai A, Prasad HK. IAP textbook on pediatric endocrinology; 2019.

29. Bonfig W, Kapellen T, Dost A, Fritsch M, Rohrer T, Wolf J, et al. Growth in children and adolescents with type 1 diabetes. J Pediatr 2012;160:900-3.e2.

30. Nambam B, Schatz D. Growth hormone and insulin-like growth factorI axis in type 1 diabetes. Growth Hormone IGF Res 2018;38:49-52.

31. Song W, Qiao Y, Xue J, Zhao F, Yang X, Li G, et al. The association of insulin-like growth factor-1 standard deviation score and height in Chinese children with type 1 diabetes mellitus. Growth Factors 2018;36:274-82.

32. Penfold J, Chase HP, Marshall G, Walravens CF, Walravens PA, Garg SK, et al. Final adult height and its relationship to blood glucose control and microvascular complications in IDDM. Diabet Med 1995;12:129-33.

33. Birkebaek N, Kahlert J, Bjarnason R, Drivvoll A, Johansen A, Konradsdottir $E$, et al. Body mass index standard deviation score and obesity in children with type 1 diabetes in the Nordic countries. $\mathrm{HbA} 1 \mathrm{c}$ and other predictors of increasing BMISDS. Pediatr Diabetes 2018;19:1198-205.

34. DuBose SN, Hermann JM, Tamborlane WV, Beck RW, Dost A, DiMeglio LA, et al. Obesity in youth with type 1 diabetes in Germany, Austria, and the United States. J Pediatr 2015;167:627-32.e4.

35. Islam ST, Abraham A, Donaghue KC, Chan AK, Lloyd M, Srinivasan S, et al. Plateau of adiposity in Australian children diagnosed with Type 1 diabetes: a 20-year study. Diabet Med 2014;31:686-90.
36. Sundberg F, Forsander G, Fasth A, Ekelund U. Children younger than 7 years with type 1 diabetes are less physically active than healthy controls: physical activity in young children with type 1 diabetes. Acta Paediatr 2012;101:1164-9.

37. Savaşhan Ç. Obesity frequency in school children and related risk factors. Türkiye Aile Hekim Derg 2015;19:14-21.

38. Blair J, McKay A, Ridyard C, Thornborough K, Bedson E, Peak M, et al. Continuous subcutaneous insulin infusion versus multiple daily injections in children and young people at diagnosis of type 1 diabetes: the SCIPI RCT. Health Technol Assess 2018;22:1-112.

39. Sherr JL, Tauschmann M, Battelino T, de Bock M, Forlenza G, Roman R, et al. ISPAD clinical practice consensus guidelines 2018: diabetes technologies. Pediatr Diabetes 2018;19: 302-25.

40. Blackman SM, Raghinaru D, Adi S, Simmons JH, Ebner-Lyon L, Chase HP, et al. Insulin pump use in young children in the T1D Exchange clinic registry is associated with lower hemoglobin A1c levels than injection therapy. Pediatr Diabetes 2014;15:564-72.

41. Zabeen B, Craig ME, Virk SA, Pryke A, Chan AKF, Cho YH, et al. Insulin pump therapy is associated with lower rates of retinopathy and peripheral nerve abnormality. PloS One 2016;11: e0153033.

42. Rosenlund S, Theilade S, Hansen TW, Andersen S, Rossing P. Treatment with continuous subcutaneous insulin infusion is associated with lower arterial stiffness. Acta Diabetol 2014;51: 955-62.

43. Rosenlund S, Hansen TW, Andersen S, Rossing P. Effect of 4 years subcutaneous insulin infusion treatment on albuminuria, kidney function and $\mathrm{HbA1C}$ compared with multiple daily injections: a longitudinal follow-up study. Diabet Med 2015;32:1445-52.

44. Szypowska A, Schwandt A, Svensson J, Shalitin S, CardonaHernandez R, Forsander G, et al. Insulin pump therapy in children with type 1 diabetes: analysis of data from the SWEET registry. Pediatr Diabetes 2016;17:38-45. 